\title{
O que entendem como papel da escola alunos, pais e professores do sistema público de ensino
}

\section{What students, parents and teachers consider as the role of school in the public school system}

\author{
Janaina Lacerda Silva ${ }^{1}$
}

\section{Resumo}

O presente artigo fundamenta-se e busca corroborar os estudos sobre políticas educacionais de pesquisadores contemporâneos, como Santomé (2001), Silva (2004), Linhares (2001, 2002), Bohn (2000). Esses estudiosos entendem que a escola pública que 'queremos' deve ser construída dentro da escola que 'temos', além disso, que políticas educacionais governamentais devem orientar propostas de uma educação realmente democráticas e fundamentalmente coletivas. Assim, por meio de uma pesquisa realizada com alunos, pais e professores do ensino médio de uma escola pública do noroeste do Paraná, objetiva-se apresentar o que os envolvidos entendem como 'o papel da escola'. Tal apresentação pretende discutir o grau de influência das concepções políticas governamentais no discurso dos alunos e o quanto a visão expressa pelos pais e professores pode revelar de que lugar estes sujeitos falam. Diante disso, como resultado de uma triangulação das visões dos três grupos participantes da pesquisa, possibilita-se a constatação de políticas educacionais 'produtivistas', 'mercantilistas' e da busca de 'invisibilidade' dos governos.

Palavras-chave: Políticas Educacionais. Papel da Escola Pública. Comunidade Educacional.

\begin{abstract}
The present article intends to corroborate to the studies on educational policies of contemporary researchers (SANTOMÉ, 2001; SILVA, 2004; LINHARES, 2001, 2002; BOHN, 2000). These researchers believe the public school which we 'want to' should have been built in the one which we have already had. In addition to that, they affirm that government educational policies should guide proposals for a real democratic school and a fundamentally collective education. Through a survey with students, parents, and high school teachers of a public school in the Northwest of Paraná, it is aimed to present what those involved understand as 'role of the school'. This presentation will discuss the degree of influence of the government policies in the speech of students and how much the vision expressed by parents and teachers can tell about the position that the person occupies. In face of this, as result of a triangulation of the visions of the three groups participating in the search, it is enabled the visualization of educational politics 'productivist', 'profiteering' and the pursuit of 'invisibility' of Governments.
\end{abstract}

Keywords: Educational Policies. Role of the Public School. Educational Community.

${ }^{1}$ Docente do Estado do Paraná. Mestranda em Letras pelo PLE-Programa de Pós-Graduação em Letras - Universidade Estadual de Maringá. Email: teacherjanaina@hotmail.com 


\section{Introdução}

De acordo com Linhares (2001), atualmente, apresentam-se muitos e incansáveis os debates de estudiosos dos movimentos sociais e educacionais sobre a imprescindibilidade da educação pública diante de um tempo de privatizações, de uma hegemonia da racionalidade e de uma política que despreza as pessoas e a própria vida. Falam, também, os pesquisadores como Silva (2004); Linhares (2001, 2002); Bohn (2000) sobre a realidade e os problemas existentes no sistema educacional público. Esses estudiosos assinalam a necessidade de uma escola que eduque para resistir e para sobreviver a uma cultura de desigualdade que se fortalece em nossos tempos.

A respeito da realidade educacional contemporânea, Santomé (2001) afirma que as instituições educacionais possuem menos recursos do que tinham há alguns anos, ao mesmo tempo em que acumulam maiores encargos quando comparados a esses períodos precedentes. Além disso, segundo o autor, o Estado busca tornarse mais invisível, ou seja, isentar-se de suas responsabilidades, oferecendo autonomia a uma instituição, ainda, despreparada. Por isso, encontramos mais dificuldade em culpabilizá-lo ou responsabililizá-lo pela administração educacional. Enfim, de acordo com esse estudioso, à margem desta 'dura' realidade das escolas, muitas vezes, ficam os alunos e seus familiares.

Em consonância com as discussões sobre as condições, responsabilidades, sonhos e desafios da escola atual, levantadas pelos estudiosos anteriormente citados, o presente artigo tem por objetivo apresentar um microcontexto da educação brasileira, por meio do que pensam os alunos, os pais e as professoras sobre o papel da escola pública. Os colaboradores da pesquisa apresentaram seus depoimentos, por meio de um questionário sobre a qualidade de ensino e o processo educacional da escola estadual que participam em nível de ensino médio no noroeste do Paraná. Esses depoimentos coletados levam-nos a analisar e discutir as concepções políticas educacionais que permeiam o discurso da comunidade escolar para, a partir disso, vislumbrar uma educação que acolha as necessidades e os interesses da comunidade que atende.

Para alcançar o objetivo do presente estudo, organizamos o trabalho, com uma apresentação inicial da fundamentação teórica que configura o atual contexto educacional. Em uma segunda seção, apresentamos o ambiente, os procedimentos e os participantes da pesquisa. Em seguida, expomos as discussões dos dados e suas possíveis interpretações. Finalmente, concluímos com as considerações sobre o que pode representar os resultados obtidos e como o lugar de onde falam os participantes da pesquisa está relacionado ao que entendem como papel da escola.

\section{O Contexto Educacional}

A fim de melhor elucidar a realidade escolar, Santomé (2001) assegura que escolas e professores têm sido encarregados de um maior número de funções: gestão econômica, planejamento de uma política educativa própria, dinamização cultural da comunidade, atenção a novos conteúdos culturais e a problemas sociais: educação contra as drogas, prevenção da AIDS, educação para a saúde, manutenção do patrimônio cultural e ecológico, entre muitos outros. No entanto, transferidas tais responsabilidades, não as acompanham os fundos financeiros necessários ao desenvolvimento desses encargos. $\mathrm{O}$ autor lembra, ainda, da presença de organismos, como o Fundo Monetário Internacional, que exigem dos governos cortes nos recursos financeiros destinados aos serviços públicos, ou seja, à educação e à saúde. No contexto brasileiro, Shiroma e Moraes (2002) questionam tais cortes orçamentários nas ações governamentais. Já que o Estado afirma lutar por melhorias na 'qualidade' da educação, como o faz cortando verbas e sendo refratário às condições objetivas das escolas públicas no Brasil. 
Frigotto (2001) assevera que organismos internacionais, principalmente o Banco Mundial, deslocam sua atuação centrada no binômio segurança-desenvolvimento para a educação, vendo-a como alívio da pobreza no Brasil e em outros países. Consequentemente, esses órgãos passam a ditar as diretrizes de organização, as prioridades e os conteúdos educacionais. Assim, segundo o autor, diante dos ajustes destes organismos financeiros, o sistema educacional passa para uma concepção produtivista e mercantilista, cujo papel é desenvolver habilidades, conhecimentos, valores, atitudes e gestões da qualidade definidas pelo mercado de trabalho para, com isso, formar em cada indivíduo um banco de competências e habilidades técnicas e cognitivas que lhe assegure empregabilidade.

Contrário às ações constatadas acima, Frigotto (2001) afirma que tal proposta educacional desvinculada de uma proposta democrática e pública de desenvolvimento sustentável, de geração de empregos e de alternativas de relações sociais, torna-se apenas um 'pacote educacional' de caráter ideológico, que não se sustenta como uma educação libertadora. Ainda de acordo com o pesquisador, a presente educação não pode ser considerada uma 'tábua de salvação' para os que correm risco de desemprego no futuro. Analisando as afirmações anteriores, podemos entender a escola, na concepção atual, como uma grande empresa que produz seus produtos/alunos e lança-os no mercado/ mercado de trabalho para serem absorvidos/ empregados. Diante disto, questionamos que aluno/ ser humano seria 'produzido' para um mercado de trabalho desumano, competitivo, tecnológico e, extremamente, dinâmico?

Segundo Santomé (2001), o aluno produzido exclusivamente para se adequar ao mercado de trabalho acaba privado de estratégias de análise e de crítica que podem gerar reflexões sobre o sistema capitalista vigente ou sobre a necessidade de propor modelos alternativos de organização da sociedade e do mundo do trabalho. Na perspectiva desse autor, a escola atual encontra-se, no mínimo, distante de uma educação que prepara o aluno para o mercado de trabalho, ao mesmo tempo em que lhe dá condições para refletir e mobilizar a construção de uma sociedade diferente da que temos. Por isso, o papel da escola deveria ser, primeiramente, estabelecer condições para uma formação humana crítica e, não, de adequação às regras de um sistema ditador.

Outro fato apresentado pelo pesquisador sobre o presente sistema educacional refere-se à redução das normas e regulamentos que prescrevem o trabalho docente. Essas reduções, em sua maior parte, são vistas como flexibilidade e autonomia para os docentes desenvolverem a organização curricular. Entretanto, com o controle dos principais grupos produtores de materiais didáticos e o poder de autorizar a edição desses materiais, os governos exercem seu poder de forma implícita sobre o sistema educacional. Consequentemente, o professor não pode se queixar do mau funcionamento da educação ou atribuir responsabilidade aos regulamentos dos órgãos competentes; desta forma, acabam por aprender a assumir toda a responsabilidade, até as que de fato não lhe pertencem, como as diretrizes curriculares educacionais.

Uma análise superficial, segundo Santomé (2001), pode indicar que o Estado oferece autonomia aos professores e que esses já apresentam uma boa formação, constantes atualizações e são capazes de tomar decisões mais reflexivas e de envolverem-se com inovações. Entretanto, a partir de nossas próprias experiências educacionais, não se torna visível o entrelaçamento da autonomia com as condições que a viabilizem. Geralmente, os investimentos em formação profissional, atualização pedagógica e cultural são reduzidos e limitados nos planejamentos orçamentários dos governos.

Diante dos exemplos de falta de recursos, da ausência de condições, do acúmulo de responsabilidades e das normas de organismos internacionais que mudam a direção da escola e sustentam a intenção de invisibilidade do Estado, Linhares (2001) aponta para todos os participantes 
do processo educativo - tais como professores, estudantes e seus familiares - como interlocutores nas discussões sobre educação. Já que a autonomia que fecunda o atual solo educativo não ordena uma ação individual e, sim, uma coletiva que se fortalece com indivíduos fortes (SILVA, 2004), ou seja, formados, informados e orientados a gerir sua própria autonomia. De tal modo, entendemos como imprescindível a necessidade de nos unirmos por uma educação definitivamente pública, igualitária e solidária que crie alternativas de sociedade.

\section{O papel da comunidade educacional}

$\mathrm{Na}$ missão da Escola, todas as pessoas são necessárias e ninguém pode ou deve delegar suas tarefas e responsabilidades. De acordo com os estudos de Santomé (2001), torna-se conveniente aprender a atrair apoios às instituições educacionais públicas. Além do apoio dos alunos e de seus familiares, há muitos outros coletivos que podem estender redes, visando traçar estratégias para criar disposições e atitudes positivas de colaboração e participação nas resoluções dos problemas educacionais. No entanto, levando em consideração o espaço do presente trabalho, focalizaremos o trabalho coletivo da escola entre professores, alunos e familiares.

Pode parecer comum que, em assuntos educacionais, todos possam opinar, já que, em algum momento de nossas vidas, conhecemos uma forma de educar, estivemos em salas de aula e assumimos um modelo escolar. Contudo, segundo Santomé (2001), o atual modelo de democracia capitalista, ao se consolidar, também, fortaleceu o discurso de que quem não sabe sobre determinado assunto deve obedecer aos que sabem. Com isso, as famílias foram desconsideradas, afastadas e desestimuladas a participar, fazendo-lhes ver que não tinham ideia do que era educar. Consequentemente, de aliada, a instituição familiar tornou-se rival da escolar.

De acordo com o exposto, anteriormente, Gil (2001) entende que o sistema educativo, prescrito por organismos como o Banco Mundial, configura- se pelo conjunto de sistemas econômicos, políticos, religiosos dos meios de comunicação e, não, pelas concepções e expectativas dos diretamente implicados: os alunos, os professores e as famílias.

Nesta lógica neoliberal de comércio, competitividade e individualismo, Santomé (2001) afirma que a intenção do governo é transformar as tradicionais 'culturas de colaboração' e de responsabilidadecoletivaem 'culturas empresariais'. Deste modo, as famílias de potenciais participantes da escola desempenhariam o papel de clientes que, algumas vezes, tentam impor suas concepções educativas às escolas. Tendo em vista o assinalado, entendemos o quanto pode ser conveniente para os governos uma política educacional que desarticule a escola e enfraqueça sua coletividade. Por isso, apontamos a urgente necessidade da escola e dos docentes buscarem a cooperação das famílias, pois, conforme afirma Adorno (1995, apud LOUREIRO, 2003), é necessário "educar para resistir à barbárie da sociedade administrada", ou seja, lutar com todas as forças contra o sistema vigente.

Diante da necessidade apresentada, a ação educativa de resistência só se configura como possível na presença de um trabalho cultural, social, ético e político, que requer a participação da família e do alunado. Inicialmente, as instituições escolares podem intimidar as famílias, em especial, aquelas com menor nível cultural e econômico. No entanto, é importante lembrar que uma das funções das instituições educacionais é colaborar para uma sociedade mais democrática e igualitária e, assim, possibilitar o acesso às informações aos que mais precisam delas, (SANTOMÉ, 2001).

Enfim, entendemos que, aliar-se às famílias para uma educação pública melhor, poderá despender da escola momentos para reuniões com a comunidade e, possivelmente, implicará a exposição da realidade e dificuldades da escola. Entretanto, corresponderia a unir-se aos que mais desejam o melhor para seus filhos e filhas. Com isso, a escola e, respectivamente, os docentes encontrariam colaboradores na busca 
da qualidade educacional para todos e não uma 'qualidade total' para poucos, (FRIGOTTO, 2001).

\section{O papel da escola}

Em nossos dias, segundo Linhares (2001), um tipo de razão e uma política etnocêntrica, machista, racista e calculista revigoram suas formas de aumentar o controle sobre o conhecimento dos saberes das instituições escolares. Consequentes disso, surgem dois ideários de escola. Em um, há o desejo de conservar e expandir os privilégios para as classes mais elevadas da sociedade. No outro, urge a compreensão das práticas sociais para, posteriormente, lutar pela apropriação de saberes que capacitem a criação de novos mundos, onde caibamos todos, com nossos sonhos e nossas responsabilidades. $\mathrm{Na}$ perspectiva da autora, a busca pelo segundo ideário de escola não pretende se aproximar fundamentalmente da luta por classes sociais igualitárias, mas por políticas públicas diferentes, mais justas, solidárias e 'includentes'.

Em busca, então, de uma escola efetivamente democrática, Linhares (2001) assegura que o sistema escolar está constantemente mudando. Em alguns momentos, torna-se refém de um esquema reprodutivo de alto poder que se encontra desgastado e, por isso, abre espaço para outros momentos, em que a escola busca modernizar-se e 'acessar um futuro milagroso'. Entretanto, a pesquisadora chama nossa atenção para a impossibilidade de separar os projetos de escolas que se almejam, dos que já estão instituídos. Por isso, torna-se ainda mais difícil transformar o que já está posto como escola, ou escolas.

Neste momento, que não se pode negar o 'apartheid' das escolas, escolas de excelência - em que os conhecimentos são adquiridos com alto consumo de recursos, ideias e informações - e escolas populares - que subsistem em regime de total negligência, alternando entre o abandono e as imposições governamentais - as políticas educacionais públicas, em grande maioria, esquecem a lógica empresarial de investimentos para se estabelecer a qualidade, ou melhor dizendo, a 'competitividade de mercado' e promovem o abandono da escola pública à sua própria sorte.

Em presença do que se configura, somos levados a refletir sobre os diferentes papeis que as escolas podem desempenhar, obedecendo a seus distintos interesses, e quão relativo seria a qualidade dentro de tão diferentes papeis. Gimenez (2005) aponta para a dificuldade de proporcionar um ensino de qualidade, quando não está claro o que se entende por essa qualidade. Pois, se a comunidade de pais e alunos, junto à sociedade, estabelecer, como papel das escolas populares, os mesmos exercidos pelas escolas de excelência - em sua maioria as particulares - teríamos, sem dúvida, um abismo entre as expectativas e os resultados. Deste ponto de vista, não seria justo esperar o que se entende por qualidade em uma, no contexto da outra. Então, o raciocínio é nos conformar que a escola pública nunca será de excelência? Certamente que não. Precisamos agir coletivamente, analisar os problemas e criar estratégias para uma escola pública melhor, dentro do que apreendemos que seja seu papel.

Linhares (2001, 2002) demonstra, no entanto, como exemplos, escolas públicas que, na luta contra o sistema de desigualdade e injustiça, alcançaram uma escola de excelência e libertadora, escolas como as dos municípios de Betim (MG) e de Chapecó (SC). Tais escolas engendram uma práxis educativa vinculada às mudanças no plano econômico e cultural centradas no exercício da democracia participativa, tendo como princípio mais evidente a reconciliação da escola com a vida, rompendo com o velho lema de preparar para um remoto amanhã.

Assim, percebemos que a escola pública que nos interessa deve ter como base sustentadora uma educação democrática participativa, na qual, docentes, alunos e professores deliberam sobre a educação que atende os interesses da comunidade, e não a imposta ou definida por governos. Contudo, o trabalho participativo da comunidade escolar 
deve primar, também, por atribuir aos governos as responsabilidades econômicas e políticas que lhes competem, exigindo, assim, da administração pública, as condições para construir a escola almejada pela comunidade escolar.

\section{Pesquisa: o Ambiente, os Participantes e os Procedimentos}

Diante do objetivo de investigar o que entendem como papel da escola, alunos, pais e professores do sistema público de ensino, coletamos dados de vinte e quatro colaboradores envolvidos no processo educacional do terceiro ano do ensino médio, no primeiro semestre do ano letivo de 2008, em uma escola pública de uma cidade do noroeste do Paraná. Os participantes da pesquisa responderam a um questionário que tinha como principal objetivo investigar suas crenças, concepções e expectativas, a partir de uma questão fundamental: 'qual o papel da escola em sua visão?'.

O questionário atendeu ao interesse de coletar os depoimentos para responder à pergunta de pesquisa: 'O que entendem como papel da escola, alunos, pais e professores do sistema público de ensino?'. Tendo em vista os estudos de Linhares (2001) que nos fundamentam, uma educação de qualidade e o papel da escola muito dependem dos objetivos e perspectivas da comunidade escolar. Assim, vislumbrou-se a pertinência de uma investigação dos interesses desta comunidade, mesmo que, em um contexto particular, a fim de se conjecturar as diretrizes para a construção de uma escola efetivamente democrática e de qualidade.

A escola, na qual realizamos a coleta, localizase na região central da cidade, de onde provêm seus 752 alunos. Considerada de pequeno porte, a instituição ocupava, no momento da coleta, o primeiro lugar no ENEM, dentre as escolas públicas do núcleo regional de educação a que pertencem. Administrada pela mesma equipe há onze anos, o estabelecimento oferecia, para sua comunidade, os cursos de ensino fundamental da $5^{\mathrm{a}}$ à $8^{\mathrm{a}}$ série em período diurno; ensino médio do $1^{\circ}$ ao $3^{\circ}$ ano, no período matutino; assim como, curso técnico, em períodos matutino e noturno.

Os colaboradores da pesquisa formam três grupos: alunos, pais e professoras. O primeiro grupo com dez alunos teve como critério de seleção o fato de cursarem o terceiro ano do ensino médio, o que acreditamos proporcionar depoimentos mais amadurecidos a partir de uma posição de maior experiência escolar. Outro critério foi estabelecido pelo grau de responsabilidade do aluno, já que esses deveriam aplicar o questionário aos seus pais e devolvê-los a uma das professoras da turma, a qual escolheu os alunos diante do critério de 'responsabilidade' e de interesse em participar/colaborar com a pesquisa. Destes alunos participantes, oito são meninas e dois meninos. Nove deles estudam em escola pública de onze a treze anos, apenas um aluno estuda só há quatro anos nessa rede de ensino. Do total de alunos participantes da pesquisa, somente três alunos estudaram em escolas particulares em algum momento da sua vida escolar.

Os pais dos alunos anteriormente apresentados foram consequentemente incorporados à pesquisa. Participaram da coleta, nove pais, já que um não devolveu o questionário levado pelo filho. Este grupo formou-se com os dados de quatro mães, quatro pais e um participante que não podemos identificar nesta apresentação porque ele não forneceu seus dados pessoais. O grau de escolaridade apresenta-se de forma diversificada, dois participantes possuem ensino superior, três concluíram o ensino médio e dois apresentam o ensino médio incompleto. Apenas um não concluiu o ensino fundamental. Todos os pais colaboradores que informaram seus dados estudaram somente em escolas públicas.

A seleção do terceiro e último grupo, as professoras participantes, teve como critério a mesma área de atuação da pesquisadora - língua inglesa - já que a intenção do questionário aplicado era também investigar o que essas professoras 
entendiam como qualidade no ensino de língua estrangeira, o que ficará para outro momento, diante do espaço do presente trabalho. As cinco professoras foram convidadas a participar da pesquisa pela pesquisadora que trabalha com as profissionais há oito anos na mesma escola pública estadual lócus da pesquisa. As professoras responderam prontamente ao questionário da pesquisa no prazo máximo de uma semana. Das cinco participantes, três não possuíam, naquele momento, contato direto com os alunos do terceiro ano; no entanto, participaram de sua formação em séries anteriores. Todas as colaboradoras têm como formação inicial o curso de Letras/Português-Inglês e especialização em nível de pós-graduação em uma das referidas áreas. Quatro professoras já trabalharam em escolas particulares, duas ainda dividiam sua carga-horária entre a escola pública e a particular.

Os três grupos de participantes da pesquisa responderam a um questionário aberto com oito questões. Segundo Mckay (2003), tal instrumento pode oferecer informações sobre a visão dos sujeitos de pesquisa diante de um processo. Já que, segundo Freitas e Borghi (2006), o discurso se constitui das diversas identidades sociais que se mostram através da materialidade linguística, pois, dependendo dos lugares de onde falam os sujeitos, esses fazem escolhas que orientam possibilidades de significação em seus discursos.

Então, os questionários respondidos dividem-se emtrês versões. Cadaversão apresentaessencialmente as mesmas perguntas, com alterações mínimas que direcionam o instrumento de coleta a cada grupo participante. As perguntas do questionário, tais como: 'Em sua opinião, há diferença entre a escola pública e a escola particular?'; 'De acordo com sua opinião, qual é o principal papel da escola?'; 'O que você entende por Educação de qualidade?', dentre outras, foram formuladas para suscitar depoimentos que corroboram o objetivo do trabalho, conforme versão disponível nos apêndices deste trabalho.
A partir do instrumento de pesquisa, cada participante teve seu depoimento analisado separadamente em cada pergunta. Após o momento de análise individual, foram confrontados os dados coletados dentro de cada grupo. Nessa etapa da análise, nas respostas da questão número um (01): 'De acordo com sua opinião, qual é o principal papel da escola?', destacaram-se dois verbos: 'ensinar' e 'educar'. Os dois verbos permitiram definir duas perspectivas quanto ao papel da escola que levaram a duas categorias de análise: a) uma que nomeamos como 'conhecimento cientifico', correspondendo ao papel da escola de 'ensinar'; b) outra que chamamos de 'formação humana' que se relaciona ao papel da instituição de 'educar'. Essa última categoria agrupou as subcategorias divididas em 'educar para vida', 'para o futuro', 'para ser cidadão'e 'para o mercado de trabalho', de acordo com os papéis da escola que emergiram dos dados de cada grupo de participante.

Após essas análises de maneira individual e coletiva, o depoimento volta a ser analisado particularmente diante da realidade de cada sujeito e de sua posição na instituição, e assim, buscamos estabelecer relações entre a posição do(s) sujeito(s) de pesquisa e sua(s) forma(s) de entender o papel da escola. Assim sendo, apresentaremos, na próxima seção, os depoimentos pertinentes à análise de cada grupo, seguidos da discussão dos dados.

\section{O Que Entendem, como Papel da Escola, Seus Participantes}

Em presença do objetivo da pesquisa, expomos o quadro 1 que apresenta os depoimentos dos dez alunos participantes. Cada aluno recebeu um número de acordo com a sequência da tabulação dos dados. Junto ao número, acrescentamos a letra "A", que indica a categoria "Aluno". 
Quadro 1 - O significado atribuído pelos alunos ao papel da escola.

\begin{tabular}{|c|c|}
\hline Conhecimento científico & Formação humana \\
\hline \multirow{3}{*}{$\begin{array}{l}\text { Conteúdo: } \\
\text { Passar todo conhecimento possível e toda informação } \\
\text { necessária para obtermos um maior desempenho... 1A }\end{array}$} & Para vida: \\
\hline & ... com a função de mostrar como é a vida. $2 \mathrm{~A}$ \\
\hline & Ensinar as pessoas sobre as coisas da vida... 3A \\
\hline \multirow{2}{*}{$\begin{array}{l}\text { Educar (ensinar) os alunos, com ensinamento } \\
\text { (conhecimento) do passado e do presente... } 2 \mathrm{~A}\end{array}$} & ... e principalmente mostrar ... como é a vida... $8 \mathrm{~A}$ \\
\hline & Para o futuro: \\
\hline \multirow[b]{2}{*}{$\begin{array}{l}\text { Ensinar ...dar uma base de ensino, pois é o que se exige } \\
\text { atualmente... 3A }\end{array}$} & Educar... preparados para o mundo lá fora... 10A \\
\hline & $\begin{array}{l}\text { Educar... e incentivar o aluno a ter um bom futuro...4A } \\
\text {... para obtermos um maior desempenho futuramente. } 1 \mathrm{~A}\end{array}$ \\
\hline \multirow[t]{2}{*}{...dar base... 4A } & Para ser cidadão: \\
\hline & Formar cidadão... 5A \\
\hline \multirow[t]{2}{*}{ Ensinar... 7A } & Educar as pessoas para ser um bom cidadão... 6A \\
\hline & ... ajudar a construir uma mente mais responsável... 7A \\
\hline Ensinar... nos desafios para ingressar na faculdade... 8A & Para o mercado de trabalho: \\
\hline Primeiramente, ensinar e nos preparar... 9A & $\begin{array}{l}\text {... estar preparado para o mercado de trabalho. } 6 \mathrm{~A} \\
\ldots \text { preparar para nos tornarmos bons profissionais. } 9 \mathrm{~A}\end{array}$ \\
\hline Ensinar... preparados para o mundo.10A & ... e queiram ter uma vida de sucesso profissional. $5 \mathrm{~A}$ \\
\hline
\end{tabular}

Fonte: a autora

Os depoimentos dos alunos, apresentados acima, coletados na questão 01 do questionário, em que se questionava 'qual é o principal papel da escola', podem evidenciar que, para os alunos, o papel da escola é tanto 'ensinar' quanto 'educar'. Certamente, definir o que significa cada um destes termos tornase bastante complexo, conforme aponta a literatura, segundo Cristóvão (comunicação verbal) ${ }^{2}$. No entanto, de acordo com os estudos da pesquisadora, 'ensinar' configura-se nos dados como passar, fornecer ou transmitir o conhecimento/informação. Assim como 'educar' sugere a preparação do aluno para a vida, o futuro, a sociedade e o mercado de trabalho.

Deste modo, somos levados a entender que os alunos veem como principal papel da escola o ensino do 'conhecimento cientifico' e o desenvolvimento da 'formação humana'. O primeiro é definido por Loureiro (2003) como treinamento, o segundo, como formação humanística. Embora a pesquisadora fale do ambiente universitário, parecem-nos caber as definições ao contexto da escola básica, pois, para a autora, o treinamento está ligado ao 'adestramento' - ao domínio de um conjunto de técnicas, sobre um vocabulário e sobre uma linguagem - já a formação humanística seria a vivência do mundo junto aos conhecimentos nele contido. Entretanto, ela nos alerta para a possibilidade de uma educação desenvolver exclusivamente o treinamento ou 'adestramento', visando à 'produtividade', postura que tornaria tal educação 'cega'. Ao mesmo tempo, uma educação voltada apenas para a 'formação', seria 'impotente'.

A visão de uma educação produtivista e mercantilista pode ser consequente das ações dos

\footnotetext{
${ }^{2}$ Vera Cristovão; durante as aulas do Programa de Pós-graduação de Estudos da Linguagem da UEL, na disciplina de Políticas Educacionais ministrada no primeiro semestre de 2008.
} 
organismos financeiros, como já ressaltamos com Frigotto (2001), somada aos dados que somos levados a evidenciar nos depoimentos dos alunos: (6A) e (9A), em que consta somente o verbo 'preparar' em relação ao mercado de trabalho, nos permitem refletir sobre a possibilidade desses alunos estarem sendo educados apenas para se 'adaptarem' ao mercado, sem uma educação que os levem, também, a 'questionar suas condições' de trabalho ou organização. O que poderia indicar uma educação que apenas 'adestra' e que não leva o aluno à criticidade.

Para melhor focalizar um dos principais papéis da escola, na perspectiva dos alunos, o de 'ensinar' e as influências políticas que este ensino pode receber, nesse momento, dos oito depoimentos que apontam para 'ensinar', consideramos apenas cinco deles em particular. Essa análise busca perceber em que perspectiva a prática de 'ensinar' estaria imbricada, em uma perspectiva mais mercantilista ou em uma humanista. Então, observamos algumas expressões usadas pelos alunos junto ao verbo 'ensinar', tais como: '...para obtermos um maior desempenho...' (1A); 'pois é o que se exige atualmente.' (3A); 'nos desafios para ingressar na faculdade...' (8A); '...nos preparar, para nos tornarmos bons profissionais...' (9A); e '...preparados para o mundo lá fora.' (10A) [ênfase acrescentada]. As expressões negritadas, nos depoimentos dos alunos, levam-nos a perceber palavras como: desempenho, exigências, desafios, bons profissionais e preparação que podem indicar as crenças dos alunos em uma organização mercantilista, exigente e competitiva que configura um sistema educacional no qual se fortalece o neoliberalismo. Assim, fundamentalmente desumano, o sistema permite emergir os ideários de que só vencem os melhores e não há espaço para todos.

Diante da última análise, podemos refletir que os discursos dos alunos não são constituídos apenas pela instituição escolar, mas também pela instituição familiar, midiática, religiosa, dentre outras. Entretanto, os depoimentos analisados foram coletados na escola e direcionam-se aos papéis dessa instituição, por isso, consideramos que o discurso capitalista seja igualmente comum a esse ambiente.

Ainda do ponto de vista dos alunos, destacamos outro principal papel da escola, o da 'formação humana'. Todos os alunos incorporaram às suas declarações um dos aspectos de uma formação humanística. No quadro 1, os depoimentos apresentam um equilíbrio dentro das subcategorias da 'formação humana', ou seja, há, na perspectiva do alunado participante, uma indicação de que o papel da escola é oferecer uma formação humana equilibrada entre os aspectos da vida, do futuro, da cidadania e do trabalho. A nosso ver, tal equilíbrio poderia ser ainda ampliado, se indicasse dois objetivos a serem cumpridos pela escola: o primeiro, formar para o momento presente - para a 'vida' e a 'cidadania' - o segundo, para um momento posterior - indicado pelo 'trabalho' e o 'futuro'.

Observamos, a partir desse momento, os depoimentos dos alunos que projetam na escola o sucesso de seu futuro.

\section{[...] um maior desempenho futuramente. (1A) \\ [...] e incentivar o aluno a ter um bom futuro...(4A) \\ [...] queiram ter uma vida de sucesso profissional. (5A)}

Embora nos pareça adequado e coerente o apontamento da escola como meio de emancipação. Destacamos que a preocupação de apenas 'preparar para o futuro' pode distanciar do contexto da escola a realidade imediata do aluno, conforme afirma Linhares (2001). Ainda, em presença de uma realidade deficiente de condições, formação e recursos, devido à falta de efetivos investimentos governamentais, nos questionamos, se as escolas podem cumprir esse esperado papel de 'formar'? $\mathrm{Ou}$ até mesmo o de 'ensinar'? Mesmo que entendamos que expectativas possam e, talvez, devam ser maiores do que a realidade, a fim de se ter sempre algo a alcançar, pensamos que na área da educação pública, que passa por constantes avaliações, esta distância entre expectativas e resultados acabe tornando-se descrédito. 
Em suma, após todas as discussões referentes aos depoimentos dos alunos, somos levados a apreender que, para este grupo, o principal papel da escola é equilibrar-se entre ensinar e educar, ou, possivelmente, ensinar para formar. Além disso, podemos constatar um discurso mercantilista do sistema capitalista vigente que permeia o ponto de vista destes participantes, marcando a perspectiva de ensino e de formação que se tem configurado na escola. Tal constatação poderia ser esperada, tendo em vista que a escola não é refratária à sociedade. Entretanto, esta concepção de educação muito afasta a escola atual da que buscamos, ou seja, da que possa promover a criação de uma sociedade mais democrática.

O 'quadro 2' proporciona a visualização dos dados referentes ao que os nove pais entendem como papel da escola. Cada um destes participantes recebeu um número, de acordo com a ordem de tabulação dos dados, e a letra "P" para identificar a categoria "Pais".

Quadro 2 - O significado atribuído pelos pais ao papel da escola.

\begin{tabular}{|c|c|}
\hline Conhecimento científico & Formação humana: Educar. 6P \\
\hline \multirow[t]{3}{*}{ Conteúdo: } & Para vida: \\
\hline & ... preparar o aluno para a vida. $2 \mathrm{P}$ \\
\hline & ... condição de vida digna. 4P \\
\hline \multirow[t]{2}{*}{ Ensinar aos alunos... 1P } & ... coisas novas no mundo. $7 \mathrm{P}$ \\
\hline & Para o futuro: \\
\hline \multirow[t]{2}{*}{ Além da transmissão de conhecimento... 2P } & Preparar os nossos filhos para o futuro. 8P \\
\hline & $\begin{array}{l}\text { Educar as pessoas para que possam ingressar em uma } \\
\text { faculdade. } 5 \mathrm{P}\end{array}$ \\
\hline \multirow[t]{2}{*}{... dando a ele educação (conhecimento)... 4P } & $\underline{\text { Para ser cidadão: }}$ \\
\hline & Educar, orientar, formar cidadão. 3P \\
\hline \multirow[t]{2}{*}{ Ensinar o aluno a aprender coisas novas no mundo. $7 \mathrm{P}$} & Formar o cidadão, dando a ele educação, cultura ... 4P \\
\hline & Para o mercado de trabalho: \\
\hline Dar um ensino-aprendizagem de qualidade. 9P & $\begin{array}{l}\ldots \text { mostrar o papel deles (alunos) no mercado de trabalho. } \\
1 \mathrm{P}\end{array}$ \\
\hline
\end{tabular}

Fonte: a autora

Apoiados nos depoimentos escritos pelos pais como resposta à pergunta 1 do questionário: De acordo com sua opinião, qual é o principal papel da escola?, os dados parecem indicar que os pais acreditam que o papel da escola seja fundamentalmente o de 'formação humanística', inclinando-se a uma formação que prepara o aluno para o futuro profissional e acadêmico, além de proporcionar o desenvolvimento de suas relações pessoais e sociais. Dos nove pais, oito podem ter seus depoimentos agrupados em uma das subcategorias da 'formação humana': para a vida, o futuro, a cidadania e o mercado de trabalho. Dentre os pais, o único que está fora das subcategorias pode situarse na categoria maior 'formação humana', pois declarou apenas 'educar.'(6P), quanto ao principal papel da escola.

A partir destas constatações, os depoimentos dos pais poderiam levar-nos a duas considerações. A primeira, poderíamos considerar um equilíbrio entre uma formação para o presente - para a vida e a cidadania - e para um momento posterior à vida 
escolar - o futuro e o mercado de trabalho - assim como parece indicar também os depoimentos dos alunos, já apresentados. Tal posicionamento dos pais apoiaria uma reconciliação da escola com a vida dos alunos no presente e divergiria de uma formação apenas para um distante amanhã. Segundo Linhares (2001, 2002), justamente, o que têm feito as escolas públicas mineira e catarinense que alcançaram a excelência.

Já uma segunda consideração da perspectiva dos pais poderia sugerir que tanto a vida e a cidadania como o futuro e o mercado de trabalho indicassem, na verdade, uma preocupação dos pais apenas com o futuro dos filhos, algo também comum às ansiedades paternas.

Posteriores às últimas considerações, outra observação nos chama a atenção nesse momento. Mesmo ao categorizarmos 'educar' como 'formação humana' e 'ensinar' como 'conhecimento cientifico', a fim de estabelecer uma organização para a análise, não podemos deixar de perceber que as duas categorias se relacionam constantemente nos depoimentos dos pais. Diante disso, parecenos significativo considerar que o conhecimento científico possa ou, talvez, deva relacionar-se com uma formação humana na qual as disciplinas e conteúdos escolares têm sua aplicabilidade e finalidade no mundo real, tanto no presente quanto no futuro do aluno.

Uma aplicabilidade dos conteúdos escolares à prática e às experiências reais parece confluir para uma educação libertadora ou 'pedagogia crítica' disseminada nas escolas pela teoria já clássica de Paulo Freire. No entanto, nos chama atenção tal constatação partir dos depoimentos escritos dos pais, grupo em que apenas dois participantes possuem curso superior, fato que provavelmente os afasta das teorias pedagógicas comuns aos meios acadêmicos. Desta forma, parece emergir, no papel da escola e no ponto de vista dos pais, uma formação humana ancorada em um ensino dos conhecimentos científicos ou um ensino dos conhecimentos científicos com fim nos diversos aspectos da formação humana.

Também, levando em consideração a escolaridade dos pais, destacamos, abaixo, um depoimento em particular que está exposto no 'quadro 2':

(Formar o cidadão, dando a ele educação, cultura e uma condição de vida digna. (4P))

O participante entende, como papel da escola, 'Formar o cidadão [...]', dar ao aluno conhecimento, embora tenha usado o termo 'educação' no lugar de 'conhecimento', de acordo com o que o contexto nos permite entender. Enfim, para ele, além de formar e ensinar, a escola tem também como papel proporcionar ao aluno 'uma condição de vida digna. '. Este dado, ao mesmo tempo em que nos remete à impotência das famílias de menor poder aquisitivo quanto à vida digna de seus filhos, por vários fatores como dificuldades profissionais ou financeiras, leva-nos a retomar a possibilidade de uma educação libertadora postulada por Freire (1996), isto é, uma educação que proporciona ao aluno condições deste evidenciar a necessidade de mudar a sociedade e/ou o mundo. De acordo com o apresentado, parece se fortalecer, no depoimento do participante (4P) em especial, o segundo ideário de escola descrito por Linhares (2001), exposto por nós em seção anterior, uma escola popular em que urge a compreensão das práticas sociais, para lutar pela apropriação de saberes que capacitem a criação de novos mundos, mais justos e includentes.

Nesse momento, parecem-nos inevitáveis algumas considerações. Não estariam os pais e os filhos confluindo para uma mesma escola? Estariam estes apontando para uma instituição que cumprisse o papel de ensinar para uma formação humana em que se possam construir melhores condições de vida? As análises nos levam a responder que sim. Entretanto, nos convida a observar outros dados referentes ao que os pais pensam sobre a escola que participam.

Neste sentido, as respostas dadas às questões 2 e 4 do questionário parecem indicar a perspectiva 
dos pais, quanto ao papel que desempenha a escola de seus filhos. Na primeira pergunta, os pais respondem à 'Como você acha que a escola de seu filho desempenha esse papel da escola? Por quê?'. Nesta questão, dos nove pais, sete responderam à pergunta com a expressão 'bem', indicando uma relativa satisfação com a escola de seus filhos. $\mathrm{Na}$ segunda pergunta que, de forma exclusiva, oferece duas outras perguntas a fim de dar mais objetividade às respostas ('Você considera de qualidade a Educação que seu filho recebe na escola dele? 'Sim. No entanto, há algo que poderia ser melhorado?' ou 'Não. O que falta para ser de qualidade?'),os pais parecem apontar para o que falta na escola de seus filhos, observe:

Sim, [no entanto, poderia haver ] um melhor aperfeiçoamento de conteúdo, para melhor aplicativo de ensino da educação. (1P)

Sim, [no entanto, poderia ser melhorado] investir nos profissionais. (2P)

Sim, a educação é de qualidade, mas a forma que ela é apresentada ao aluno não. (4P)

Sim, [no entanto, poderia ser melhorado] o método de avaliação. (5P)

Sim. [no entanto, poderia ser melhorado] o método de ensino. (7P)

Sim. Na minha opinião, não há o que ser mudado, além do pulso firme dos professores. (8P)

Sim, mas a educação que exija o aprendizado. Que verifique se o aluno está aprendendo ou não. (9P) [Ênfase e trechos acrescentados]
A partir dos trechos destacados, nos depoimentos dos pais, podemos assinalar o que não parece colaborar para uma educação de qualidade 'os investimentos em profissionais', o 'método de avaliação', 'o método de ensino', 'o pulso firme dos professores', 'a forma como [o conteúdo] é apresentado' e 'a verificação da aprendizagem'. Um dos elementos destacados nos leva a considerar a falta de investimentos no professor por parte do governo. Por outro lado, todos os outros elementos, na perspectiva dos pais, parecem implicar atribuições próximas ao papel do professor. Desta forma, o governo encontra-se aparentemente distante da falta de qualidade na educação; a instituição escolar isenta de suas responsabilidades e o professor, culpabilizado pelos problemas da escola. Esta possibilidade de interpretação pode ser bastante coerente, diante de um sistema em que os sujeitos são responsabilizados e os governos ficam livres de seus compromissos.

Nesse momento, posterior às observações que nos conduziram a entender que os pais acreditam que a escola de seus filhos cumpre relativamente 'bem' seu papel e que se trata de uma instituição de qualidade, embora destaquem, como principal ponto de problema, o professor, passamos ao 'quadro 3' que corresponde à tabulação dos dados das professoras. Essas participantes também receberam um número, de acordo com a ordem de digitação dos seus dados, e as letras "PR", para indicar a categoria "Professores".

Quadro 3a - O significado atribuído pelas professoras ao papel da escola.

\begin{tabular}{|l|l|}
\hline \multicolumn{1}{|c|}{ Conhecimento científico } & \multicolumn{1}{c|}{ Formação humana } \\
\hline Conteúdo: & Educar. 1PR \\
O principal papel da escola é transmissão de conteúdos, & $\begin{array}{l}\text { Oferecer educação de qualidade a todos os alunos, sem } \\
\text { qualquer distinção. 5PR } \\
\text { conhecimentos. 2PR }\end{array}$ \\
$\begin{array}{l}\text { Garantir o conhecimento e aprendizagem para todos } \\
\text { dentro da escola. 3PR }\end{array}$ & \\
O principal papel da escola é ensinar os conteúdos... & \\
$4 \mathrm{PR}$ & \\
\hline
\end{tabular}

Fonte: a autora 
Diante da imprecisão do depoimento quanto ao papel da escola da participante (1PR) com apenas o termo 'Educar.' e o da (5PR) 'Oferecer educação de qualidade... ', sem uma consideração que nos pudesse direcionar, coletamos os depoimentos das respectivas professoras nas respostas dadas à questão 3 do questionário: ' $O$ que você entende por Educação de qualidade? 'Observe-os: 'Transmissão de conteúdo de qualidade...' (1PR) e '...trabalhar o aluno todo, buscando passar os conhecimentos cientifico e humano.' (5PR)
Assim, após esses últimos dados, passamos as participantes (1PR) e (5PR) para a categoria 'conhecimento cientifico', ao mesmo tempo em que mantivemos também a professora (5PR) na categoria 'formação humana', já que, na resposta à pergunta 3 do questionário, que nos auxilia no momento, a participante aponta para as duas direções, formação científica e humana. Deste modo, o quadro passa por uma reorganização:

Quadro 3b - O significado atribuído pelas professoras ao papel da escola.

\begin{tabular}{|l|l|}
\hline \multicolumn{1}{|c|}{ Conhecimento científico } & \multicolumn{1}{|c|}{ Formação humana } \\
\hline$\underline{\text { Conteúdo: }}$ & $\begin{array}{l}\text {...trabalhar o aluno todo, buscando } \\
\text { passar o conhecimento científico e } \\
\text { humano. 5PR }\end{array}$ \\
Garantir o conhecimento e aprendizagem para todos dentro da escola. 3PR & \\
O principal papel da escola é ensinar os conteúdos... 4PR & \\
Transmissão de conteúdo de qualidade... 1PR & \\
...trabalhar o aluno todo, buscando passar o conhecimento científico e humano. 5PR & \\
\hline
\end{tabular}

Fonte: a autora

Consequente aos resultados, os quais nos parecem sugerir que todas as professoras participantes entendem como principal papel da escola o 'ensinar', ou 'passar', 'informar' o conhecimento produzido cientificamente pela humanidade, poderíamos entender que essas professoras, por serem de língua estrangeira, pendem apenas para o ensino de línguas que focaliza o conteúdo, o praticado nos institutos de idiomas. O que, sem dúvida, pode nos parecer intrigante, já que o que se orienta nos documentos oficiais, principalmente no paranaense, é justamente o ensino da língua estrangeira que contribui para a formação consciente e crítica. (PARANÁ, 2006). Talvez, nem tão intrigante assim, pois, de acordo com nosso trabalho anterior, a falta de identificação com uma proposta de ensino pode levar tal proposta a permanecer apenas nos documentos oficiais. (SILVA, 2007)
Ainda, perante a definição do principal papel da escola exposta pelas professoras, é possível que signifique 'eu quero ensinar', diante dos inúmeros encargos que essas acumulam e da impossibilidade de os atenderem por causa das condições que não possuem. Ou, ainda, que tal posicionamento indique a tentativa de se aliviar do sentimento de 'culpa', consequente dos encargos não cumpridos. O que, segundo Linhares (2001), torna-se comum, no contexto ideológico configurado, que as vítimas acabam por passar por 'culpados', pois, em uma sociedade em que as responsabilidades se disfarçam, aumenta-se a busca de 'culpados'/'bodes expiatórios'. Assim, podemos entender que os professores, pela proximidade que estão do processo educativo e da grande responsabilidade que possuem diretamente sobre eles, tendem a formar menor expectativa quanto ao papel da escola para que, diante da realidade, os resultados possam 
ser alcançados e, consequentemente, deixem de ser os 'bodes expiatórios'.

Após a apresentação e a análise dos dados de cada grupo: alunos, pais e professores; buscamos investigar os sentidos diante da comparação das visões dos três grupos, o que nos parece oportuno nesse momento. Enquanto as professoras se inclinam para o 'ensinar' e os pais pendem para um 'formar' ancorado no 'ensinar', os alunos, os mais jovens em relação às outras categorias, são justamente os que mantêm maior equilíbrio entre o 'ensinar' e o 'educar/formar'. Isso pode indicar que os alunos recebem influência dos dois discursos, a soma do que dizem os pais e os professores. Contudo, acreditemos que seja pouco provável que os professores apontem verbalmente em sala de aula apenas para o 'ensinar'. Tendo em vista que deva ser notório o discurso que é vigente na escola: de 'formar para vida', para o 'mercado de trabalho', '[...] que a escola é importante para o futuro [...]', então, por que os professores dizem para os alunos o que nem eles acreditam? Antes de tentarmos responder a esta pergunta, voltamos a refletir sobre por que os alunos se encontram tão equilibrados entre os dois papeis que definem como da escola.

Perante o levantado, é possível que os alunos, devido seu espírito jovem, mesmo diante do discurso que lhe é apresentado e do desconhecimento da 'extensão' das dificuldades da escola, de fato, acreditem, ao mesmo tempo em que esperam que a escola deva 'ensinar' e 'educar/formar'. Para esses alunos, possivelmente, sejam mais frustrantes os resultados da educação pública brasileira, pois, são deles, as maiores expectativas. Desta forma, eles alimentam ainda, em suas perspectivas, o mais complexo papel da escola, já que, no discurso, o considera possível.

Então, os professores, os que provavelmente mais sofrem com as condições, ao falarem, nas salas, o que parecem apresentar os dados analisados, não acreditam, ou não esperam mais uma escola que forme o aluno em diversos aspectos da vida, fato que pode indicar a dificuldade de assumir para seus alunos que não conseguem fazer o que talvez entendam, como mínimo, 'ensinar'.

Já os pais, em oposição às professoras, ao parecer valorizar mais a formação humana, como principal papel da escola, no lugar do conhecimento científico, embora conciliem as duas categorias que de fato não são excludentes, levam-nos a considerar que este posicionamento possa falar mais da posição em que falam os sujeitos, isto é, podem entender que a escola deva preparar o aluno para a 'vida real', já que falam da escola, também, com relação às experiências que tiveram no passado, 'em seus tempos de menino', e, possivelmente, eles não sintam que tenham sidos preparados para 'o futuro' ou 'para uma vida digna'.

Diante de tal quadro, de perspectivas que se relacionam e diferenciam-se sobre o papel da escola, nos torna ainda mais evidente a urgente necessidade de diálogo entre família, professor e aluno.

\section{Considerações Finais}

Finalizada a análise dos dados, entendemos que os significados atribuídos pelos sujeitos ao papel da escola podem estar relacionados a diversos fatores: o quanto o sujeito conhece a realidade escolar; a que distância participa dela e as experiências pessoais que possui. Desta forma, os alunos têm as maiores expectativas, indicando um equilíbrio entre o 'conhecimento' e a 'formação humana'; os professores relativamente menos, destacando apenas o principal, a preocupação em relação ao 'conhecimento científico', o que levaria a uma educação "cega"; e, talvez, os pais apontem o essencial, ou seja, uma educação formadora que ganhe sentido durante a vida, com o cuidado de não torná-la 'impotente'.

Além disso, os dados nos permitem conjeturar que, atualmente, as responsabilidades concentramse nos professores, que não podem ser isentos de suas responsabilidades, mas também não devem receber 
todos os encargos. Pensamos que possivelmente se configure algo cíclico: a escola não forma adequadamente, a universidade não cumpre seu papel e o profissional não atende as expectativas. Contudo, isto pode atingir outras instituições, outras áreas: saúde e segurança pública. Então, a questão pode parecer colossal e, ao mesmo tempo, pontual, o problema é o professor, o policial ou o médico, mesmo quando usamos genericamente a escola, a polícia ou a saúde. Neste quadro, não parece haver ausência dos governos, mas falta de competência das pessoas, falta de voluntários na escola e nos hospitais. Enfim, a realidade nos aparece turva ou, possivelmente, distorcida por aqueles que deveriam nos fornecer as lentes para enxergá-la, sejam eles os profissionais, as instituições e os governos.

Por fim, o quadro que se apresenta pode, na verdade, ser consequência da força que tem o sistema vigente sobre nossa forma de pensar. Agimos todos, mas como se estivéssemos amarrados por elásticos, os quais nos permitem movimentar até o ponto que os dominantes nos permitem. Caso tentemos ir além, somos puxados de volta, o que provavelmente nos deixa cansados diante da realidade e nos faz desistir.

Diante disto, este trabalho atende ao que se propôs, isto é, discutir o que pensam os pais, alunos e professores, para confluírem seus interesses e necessidades e para se perceber os caminhos da construção de uma escola pública efetivamente democrática, apoiando a coletividade dentro da instituição, a fim de se reconhecer as responsabilidades governamentais e individuais. Assim, o trabalho em rede, as reuniões de ideias, o agrupamento de forças, a luta pelos nossos direitos, a busca pelas responsabilidades do Estado e o que mais possa nos fortalecer como indivíduos e coletivo e que possa nos permitir alcançar o 'elástico' um do outro e, em seguida, cortá-lo. Depois, poderemos nos movimentar em uma sociedade realmente democrática, na qual os resultados das escolas correspondentes às nossas expectativas.

\section{Referências}

BOHN, Hilário I. Os aspectos 'políticos' de uma política de ensino de línguas e literaturas estrangeiras. Linguagem \& Ensino, Pelotas, v. 3, n. 1, p. 111-138, 2000.

FREIRE, Paulo. Pedagogia da autonomia: saberes necessários à prática educativa. São Paulo: Paz e Terra, 1996.

FREITAS, Maria Adelaide de; BORGHI, Carmem Ilma Belincanta. O si-mesmo constitutivo dos sentidos de professores de inglês sobre um curso de formação continuada. Revista Intercâmbio, São Paulo, v. 15, 2006.

FRIGOTTO, Gaudêncio. Reformas educativas e o retrocesso democrático no Brasil nos anos 90. In: LINHARES, Célia. (Org.) Os professores e a reinvenção da escola: Brasil e Espanha. São Paulo: Cortez, 2001. p. 57-80.

GIL, Juana Maria Sancho. É possível aprender da experiência? In: LINHARES, Célia. (Org.). Os professores e a reinvenção da escola: Brasil e Espanha. São Paulo: Cortez, 2001. p. 81-114.

GIMENEZ, Telma. Políticas governamentais, mídia e ensino de línguas estrangeiras. In: GIMENEZ, Kilda Maria Prado. (Org.). Contribuições na área de línguas estrangeiras. Londrina: Moriá, 2005. p. 91-104.

LINHARES, Célia. (Org.). Os professores e a reinvenção da escola: Brasil e Espanha. São Paulo: Cortez, 2001.

. De uma cultura de guerra para uma de paz e justiça social: movimentos instituintes em escolas públicas como processos de formação docente. In: LINHARES, Célia.; LEAL, Maria Cristina. (Org.). Formação de professores: uma crítica à razão e à política hegemônica. Rio de Janeiro: D\&A, 2002. p. 103-129.

LOUREIRO, Isabel Maria. Universidade pública e neoliberalismo. In: BARBOSA, Raquel Lazzari Leite. (Org.). Formação de educadores: desafios e perspectivas. São Paulo: UNESP, 2003. p. 491-500.

MCKAY, Sandra Lee. O Professor reflexivo: guia para investigação do comportamento em sala de aula. São Paulo: Special Book Services Livraria, 2003. 
PARANÁ. Secretaria de Estado da Educação. Diretrizes curriculares de língua estrangeira moderna para a educação básica. Curitiba: SEED, 2006.

SANTOMÉ, Jurjo Torres. O professorado em época de neoliberalismos: dimensões sociopolíticas de seu trabalho. In: LINHARES, Célia. (Org.). Os professores e a reinvenção da escola: Brasil e Espanha. São Paulo: Cortez, 2001. p. 17-20.

SHIROMA, Eneida Oto; MORAES, Maria Célia Marcondes de. Política educacional. 2. ed. Rio de Janeiro: D\&A, 2002.

SILVA, Janaina Lacerda. DCEs: o que pensam os professores de inglês paranaenses sobre a atual proposta curricular e metodológica de seu Estado e como reagem diante de sua implantação. 2007. 77 f. Monografia (Especialização em Formação de Professor de Língua Estrangeira - Língua Inglesa) Universidade Estadual de Maringá, Maringá, 2007.

SILVA, Waldeck Carneiro da. Formação de professores para a educação básica na universidade e as políticas neoliberais. In: LINHARES, Célia Frazão Soares. (Org.). Formação continuada de professores: comunidade científica e poética - uma busca de São Luiz do Maranhão. Rio de Janeiro: D\&A, 2004. p. 113-132.

\section{Apêndice}

\section{Questionário respondido pelos alunos}

Prezado/a aluno/a,

Como aluna do curso de especialização de Políticas Educacionais da UEL, realizo, no momento, um estudo sobre a atual Educação Básica da Rede Pública do Estado do Paraná. Busco investigar a visão dos alunos sobre a Educação que recebem em suas escolas. Para tanto, gostaria de contar com sua preciosa colaboração para responder o questionário abaixo. Não há respostas certas ou erradas, o que importa é que elas sejam as mais sinceras possíveis para que o trabalho apresente resultados autênticos. Caso o espaço deixado para as respostas seja insuficiente, o verso da folha poderá ser usado, indicando-se o número da pergunta sendo respondida. De acordo com a ética da pesquisa, asseguramos que a procedência dos dados será mantida sob sigilo.

Desde já agradeço sua colaboração.

Pseudônimo:

Data de nascimento:

Sexo: ( )F ( )M Série:

Ensino:

Turno:

Há quantos anos estuda em escola pública?

Já estudou em escola particular? ( ) Sim ( ) Não.

Em sua opinião, há diferença entre a escola pública e a escola particular? Comente.

\section{Questionário}

1- De acordo com sua opinião, qual é o principal papel da escola?

2- Como você acha que sua escola desempenha esse papel? Por quê?

3- O que você entende por Educação de qualidade?

4- Você considera Educação de qualidade a que você recebe na sua escola?

( ) Sim. No entanto, há algo que poderia ser melhorado?

( ) Não. O que falta para ser de qualidade?

5- Como você se sente diante dessa Educação recebida?

6- Usando como exemplo suas aulas de inglês, como elas são?

7- Quais necessidades você acha que as aulas 
de inglês devem atender? Suas aulas atendem essas necessidades?

8- Que sugestões você teria para dar diante das necessidades que você apontou na questão 7 ? 
Silva, J. L. 